\title{
PERANCANGAN PEMETAAN MODEL KOMPETENSI DI TEMPAT KERJA BERBASIS SISTEM OLAP
}

\author{
Raswa \\ Program Studi Teknik Informatika, Politeknik Negeri Indramayu \\ Email: raswa@polindra.ac.id
}

\begin{abstract}
Abstrak
Profil lulusan sesuai kebutuhan kompetensi di tempat kerja menjadi sasaran pembelajaran yang sangat diupayakan dalam pendidikan vokasi. Penelitian ini mengupayakan suatu rancangan sistem On Line Analytical Processing (OLAP) untuk dapat mengatasi masalah tentang kesulitan dalam pemetaan model kompetensi yang sedang dilaksanakan dan akan dikembangkan di tempat kerja. Tujuan rancangan ini diharapkan dapat membantu dalam perumusan profil lulusan, dan dapat dimanfaatkan sebagai sumber informasi dalam pengembangan kurikulum dan capaian pembelajaran pada pendidikan vokasi. Penelitian dirancang melalui penelitian rekayasa dengan kuasi-eksperimen yang bersifat laboratori-eksplanatori dengan model incremental, dan teknik analisis data adalah deskriptif-evaluatif. Objek penelitian adalah model kompetensi Network Administrator dari Peta Kompetensi Okupasi Teknik Informasi dan Komunikasi. Simpulan yang diperoleh adalah model kompetensi dapat diekstrak menjadi data multidimensi sehingga melalui implementasi rancangan sistem OLAP berbasis Python tersebut dapat ditemukan aspek-aspek kritis model kompetensi. Saran penelitian lanjutan adalah perlu dilakukan penelitian lapangan dalam pengembangan sistem OLAP untuk pemetaan model kompetensi dengan menggunakan teknologi Machine Learning dan Deep Learning.
\end{abstract}

Kata Kunci: OLAP, Python programming, Model kompetensi, Aspek kritis kompetensi

\begin{abstract}
Graduate profile matches with needed competency by the workplace to be very important learning target sought in the vocational education. This research worshe a On Line Analyical Processing (OLAP) System Design, it can solve to competency model mapping problem, that is done and developed in workplace. This design aim to be helped in formulation of the outcome's profile, and to be used as source's information to curriculum development and learning outcome on vocational education. This research is designed as engeneering research with laboratory-explanatory on quasi-experiment by incremental model, and data analytical technic is descriptive-evaluative. As research object is The Network Administrator of the Competency Ocupation Mapping on Communication and Imformation Technic.The conclutions obtained the competency model can be extracted to be multidimensional data so by implementation the OLAP system design can be founded the critical aspects of the competency model. Futher research recommendations are needed field research in OLAP system development for the mapping of competency model by Machine Learning and Deep Learning Technology.
\end{abstract}

Keywords: OLAP, Python programming, Competency model, Competency critical aspects

\section{PENDAHULUAN}

Pendidikan vokasi sebagai bidang Technical and Vocational Education and Tranning (TVET) memiliki peran strategis dalam pembangunan suatu bangsa. Pendidikan diharapkan menjadi faktor kunci pembangunan, namun TVET menjadi kunci utamanya (the master key), karena TVET dapat membekali keahlian kerja (vocational expertice) kepada seseorang (Tuisawau dalam InWEnt, 2009:161). Pendidikan vokasi diharapkan sebagai faktor kunci untuk meningkatkan dan memelihara 
daya saing (convetitiveness) dari suatu perusahaan atau ekonomi nasional (Finlay, 2005:3).

Dengan potensi bonus demografi dan jumlah angkatan kerja pada Februari 2018 sebanyak 133,94 juta orang (BPS, 2018), Indonesia sangat memiliki peluang dalam meningkatkan daya saing perusahaan dan ekonomi nasionalnya melalui pendidikan vokasi. Namun demikian Kepala Bapennas RI, Bambang P.S. Brodjonegoro menilai bahwa penerapan vokasi di dunia pendidikan di Indonesia dianggap belum maksimal. Kualitas lulusan Sekolah Menengah Kejuruan (SMK) maupun Politeknik tidak selalu memenuhi kualifikasi penyedia kerja sehingga masih banyak pengangguran, padahal vokasi menjadi solusi cepat untuk mengatasi masalah pengangguran. Hal itu tentu bukan kesalahan pemberi kerja karena perusahaan manapun ingin sumber daya manusia yang layak diupah sesuai kebutuhan mereka, kemungkinan penyebabnya antara lain adalah kompetensi calon pekerja itu kurang, jenis kompetensi yang dibutuhkan oleh perusahaan belum dipelajari atau didalami semasa menempuh pendidikan, prakteknya kurang, kesempatan pengembangan diri saat ia magang terbatas, kurikulum pendidikan vokasi sudah kurang relevan lagi mengingat kebutuhan pasar kerja sangat dinamis dan terus berkembang seiring waktu (Kompas.com, 13/6/2019).

Itulah sebabnya penulis berpendapat betapa pentingnya lembaga pendidikan vokasi membangun hubungan (connectivity atau link) dengan perusahaan sebagai tempat kerja (workplace). Jika hubungan antara lembaga pendidikan vokasi dengan tempat kerja terbangun dengan baik, maka akan terjadi transformasi pengetahuan dari tempat kerja ke lembaga pendidikan vokasi (Stenstr"om, 2009:12). Dalam konteks itu, rumusan masalah umumnya adalah bagaimanakah media konektivitas dan transformasi pengetahuan, baik teoritis maupun praktis, dari tempat kerja ke lembaga pendidikan vokasi, sehingga pengembangan kurikulum dan penetapan profil lulusan pendidikan vokasi itu relevan dengan kebutuhan model kompetensi di tempat kerja? Secara spesifik, rumusan masalah penelitian ini adalah bagaimanakah rancangan sistem OLAP untuk pemetaan model kompetensi di tempat kerja sehingga diperoleh aspek-aspek kritis kompetensi? Bagaimanakah rancangan sistem OLAP dapat mendeskripsikan tentang indikatorindikator aspek kompetensi pada setiap kreteria unjuk kerja dari elemen kompetensi terhadap dimensi unit kompetensi atau model kompetensi?

Dengan melihat pentingnya solusi masalah konektivitas antara tempat kerja dengan lembaga pendidikan vokasi tersebut maka penelitian ini bertujuan memperoleh rancangan sistem OLAP dalam rangka memvisualisasikan peta model kompetensi di tempat kerja. Penelitian ini adalah salah satu cara untuk berkontribusi terhadap pengembangan program link and match yang sedang diterapkan pada pendidikan vokasi di Indonesia. Hasil penelitian ini diharapkan untuk dapat memantau perkembangan model kompetensi yang dilaksanakan dan dikembangkan di tempat kerja.

\section{- Sistem OLAP}

On Line Analytical Processing (OLAP) merupakan sebuah tool berupa software, atau pendekatan dalam pemrosesan pada database, yang di dalamnya dilakukan ekstraksi data-data dari data warehouse untuk menjadi informasi atau pengetahuan, serta menyediakan navigasi data ke pengguna awam agar dapat secara interaktif memperoleh query. Software OLAP merupakan server informasi yang membolekan pengguna untuk melakukan akses cepat ke data (Wrembel, R., Concilia, C., 2007:231-232).

OLAP sebagai tool, sistem, dan konsep untuk melakukan analisis data secara dinamis, yang meliputi tahapan mencipta, memanipulasi, menampilkan, serta memformulasikan model analisis data. OLAP memiliki kemampuan berupa agregasi data, query yang lebih kompleks, memiliki historical data, menyimpan data ke dalam skema data multidimensi. OLAP adalah teknologi database yang umum digunakan untuk pemrosesan data dalam struktur multidimensi. Untuk itu, OLAP memiliki lima konsep yaitu Fast, Analysis, Shared, Multidimensi-onal, Information (FASMI). OLAP memanfaatkan teknik analisis data multidimensi yang menyediakan dukungan terhadap edvance database, dukungan arsitektur client-server, dan interface yang mudah digunakan oleh pengguna awam (Wang L., Jajodia,S., Wijesekera, D., 2007:14-16).

Dari konsep OLAP sebagaimana yang telah diuraikan maka OLAP sebagai sistem terdiri dari komponen-komponen, yaitu: data multidimensi, database multidimensi, arsitektur client-server, query atau akses data, visualisasi data atau informasi dalam multidimensi.

\section{- Data Multidimensi Dalam Model Kompetensi}

Model kompetensi adalah alat bantu (tool) untuk mendeskripsikan kompetensi-kompetensi yang dibutuhkan untuk melaksanakan peran spesifik dalam suatu tugas, pekerjaan, organisasi, atau industri (Ennis, 2008:34). Suatu model kompetensi menggambarkan kombinasi pengetahuan, 
keterampilan, dan karakteristik-karakteristik yang dibutuhkan untuk sebuah peran dengan peforma secara efektif dalam organisasi, dan digunakan sebagai alat bantu sumber daya manusia untuk menyeleksi, melatih dan mengembangkan, penilaian, dan rencana suksesi (Sanghi,S., 2007:2026). Model kompetensi atau framework kompetensi adalah suatu himpunan dari kompetensikompetensi-sebuah blueprint untuk sukses (Zuppo, 2012: 7). Secara sederhana Fogg (1999) menjelaskan bahwa competency model is a behavioral job description that must be defined by each occupational function and each job.

Pengertian model kompetensi di atas menyebutkan bahwa model kompetensi merupakan sebuah panduan yang terdiri dari serangkaian kompetensi yang dibutuhkan oleh seseorang untuk mencapai kinerja yang superior atau unggul di dalam melakukan suatu pekerjaan. Model kompetensi juga berarti gambaran tertulis dari kompetensikompetensi yang dibutuhkan untuk mencapai keberhasilan secara penuh atau kinerja yang patut dicontoh di dalam kategori pekerjaan, tim kerja, departemen, divisi, atau organisasi.

Model kompetensi terdiri dari unit-unit kompetensi, dimana setiap unit kompetensi mencakup beberapa elemen kompetensi, dan setiap elemen kompetensi meliputi kreteria-kreteria unjuk kerja (KUK). Untuk setiap KUK memiliki dimensi sebagai aspek pembentuk kompetensi, yaitu aspek pengetahuan, aspek sikap kerja, dan aspek keterampilan. Aspek-aspek tersebut akan merupakan data multidimensi yang dapat mendeskripsikan model kompetensi.

Penerapan data multidimensional memiliki banyak model, diantaranya adalah model cube atau kubus. Struktur data multidimensi model cube ditunjukan melalui gambar berikut:

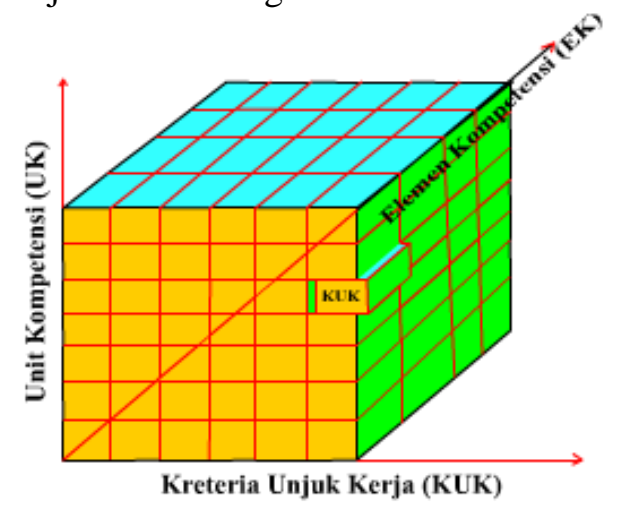

Gambar 1. Struktur Data Multidimensi Model Cube

Berbeda dengan data tabel relasional dimana data-data digital yang atribut-atributnya teratur, tersetruktur, dan tersimpan dalam database, data multidimensional memiliki atribut-atribut data digitalnya dibedakan menjadi atribut pengukuran dan atribut dimensi, memiliki struktur data dalam tabel multidimensional agar mempermudah analisis data, pengambilan keputusan, pemrosesan data dan akses informasi, kemudian tersimpan dalam multidimensional database (MDDB).

Data multidimensional model cube ditandai oleh beberapa fitur, antara lain: Slicing (pemotongan data berdasarkan kategori dan dimensi tertentu), Dicing (penyaringan data multidimensional tertentu), Pivoting (memutar visualisasi data dalam perspektif kubus), Drill Down (memecah untuk ditampilkan secara hirarki ke bawah), Consolidation (pengumpulan kembali dari proses visualisasi fitur drill down) (Pratama, 2018:36-44).

\section{METODE}

\section{- Desain Penelitian}

Berdasarkan bidang ilmu, tujuan yang akan dicapai, dan rumusan masalah yang diajukan, maka penelitian ini tergolong dalam tipe penelitian rekayasa dan bersifat eksplanatori. Pendekatan penelitian dilakukan secara one-short menggunakan metode kuasi-eksperimental dengan model Incremental. Dipilih kuasi-eksperimen karena subjek penelitian berupa rancangan sistem OLAP telah ditetapkan, dan dipilih model Incremental karena rumusan model kompetensi di tempat kerja akan terus berkembang pada masa mendatang (Klein,A.D.,2007: 172-173). Pemetaan model kompetensi dilakukan melalui deskripsi tentang penyebaran dan proporsi indikator aspek-aspek kompetensi akan menyingkap aspek kritis kompetensi dalam suatu model kompetensi. Penelitian dilaksanakan di laboratorium Research Center Teknik Informatika Politeknik Negeri Indramayu.

Model kompetensi di tempat kerja dalam penelitian ini mengambil dari dokumen Peta Kompetensi Okupasi bidang Teknik Komunikasi dan Informasi (TIK) Nomor: 127/KOMINFO/ BLSDM/ KS.01.07/7/ 2017, yang merupakan populasi penelitian. Populasi penelitian dari dokumen tersebut menurut penulis dapat menggantikan model kompetensi pada lapangan kerja di Perusahaan atau Industri, karena Peta Kompetensi Okupasi bidang TIK itu telah ditetapkan dalam rangka memastikan tersedianya sumber daya manusia kompeten dan profesional di bidang informatika, yang bertitik-tolak dari sejumlah dokumen utama seperti ASEAN ICT Skill Standards, ASEAN Qualification Reference Framework, ASEAN Guiding Principles for Quality Assurance and Recognition of Certificiation, dan 
Strategi Pengembangan Penerapan Standardisasi dan Sertifikasi TIK yang harmonis dengan ASEAN ICT Skill Standard telah diterbitkan sebagai acuan referensi. Sampel penelitian adalah Network Administrator, yang mencakup unit-unit kompetensi, antara lain: merancang topologi jaringan, merancang keamanan jaringan, mengkonfigurasi routing pada perangkat jaringan antar autonomous system, memonitor keamanan dan pengaturan akun pengguna dalam jaringan komputer, mengatasi serangan pada jaringan, mengidentifikasi sumber kerusakan, memperbaiki kerusakan konfigurasi jaringan, mengoptimalkan kinerja sistem jaringan, melakukan backup dan restore konfigurasi perangkat jaringan.

Sebagai unit analisis dalam penelitian ini adalah Kreteria Unjuk Kerja (KUK) dengan variabel penelitian berupa aspek-aspek penyusun KUK, yaitu: Aspek Sikap Kerja (A), Aspek Pengetahuan (C), dan Aspek Keterampilan (P).

Bahasa pemrograman dalam perancangan sistem OLAP menggunakan Python, satu jenis bahasa pemrograman interpreter tingkat tinggi, open source, multi platform, multi vendor, dan memiliki banyak package-package pendukung. Beberapa package pendukung yang digunakan dalam penelitian ini, antara lain: framework Django, Numpy, Pandas, Matplotlib, mpld3, dan toolkits.mplot3D. Framework Django adalah framework yang bekerja dalam lingkungan bahasa pemrograman python yang mendukung penggunaan mysql dan sqlite3.

Spesifikasi rancangan OLAP dapat dirinci sebagai berikut:

a. Menyediakan navigasi sebagai interface data ke pengguna awam agar query dilakukan secara interaktif.

b. Menyediakan dukungan arsitektur clientserver sehingga berfungsi sebagai server informasi dengan akses data yang cepat.

c. Melakukan analisis data secara dinamis melalui pemanfaatan teknik analisis data multidimensi.

d.Menyimpan data ke dalam skema data multidimensi.

e. Kemampuan melakukan agregasi data.

f. Data bersifat historis (historical data).

g.Menampilkan dan memformulasikan model analisis data multidimensi untuk membantu para pembuat keputusan.

\section{- Definisi Operasional}

Definisi operasional dari variabel-variabel penelitian ini sebagai berikut: a. Variabel aspek Pengetahuan/Kognitif (C) adalah dimensi penyusun kompetensi kerja yang memiliki indikator tingkatan penguasaannya meliputi: mengingat $(\mathrm{C} 1)$, memahami (C2), menerapkan (C3), menganalisis (C4), mengevaluasi (C5), dan menciptakan (C6).

b. Variabel aspek Sikap Kerja (A) adalah dimensi penyusun kompetensi kerja yang memiliki indikator tingkatan perilaku meliputi: menerima (A1), merespon (A2), menghargai (A3), mengorganisasikan (A4), dan karakterisasi nilai (A5).

c. Variabel Aspek Keterampilan (P) adalah dimensi penyusun kompetensi kerja yang memiliki indikator tingkatan kecakapannya meliputi: meniru (P1), memanipulasi (P2), presisi (P3), artikulasi (P4), dan naturalisasi (P5)

\section{- Prosedur Penelitian}

Sesuai dengan metode penelitian model Incremental, menurut Klein, A.D. (2007:173) maka prosedur penelitian disusun sebagai berikut:

a. Dilakukan penentuan kebutuhan atau analisis kebutuhan berupa analisis aspekaspek kompetensi untuk keperluan membangun suatu sistem OLAP yang sesuai untuk pemetaan model kompetensi. Kegiatan pada tahap ini disebut Requirement Step.

b. Dilakukan proses spesifikasi sistem OLAP dimana menggunakan analisis kebutuhan sebagai acuannya.

c. Dilakukan perancangan software dengan menggunakan bahasa pemrograman Python dan package-package pendukung yang diperlukan, seperti Framework Django, Pandas, Numpy, Matplotlib.patches, Matplotlib.mplot3d, dan mpld3.

d. Dilakukan pengkodean.

e. Dilakukan pengujian dari rancangan software OLAP yang telah dibuat.

f. Dilakukan perbaikan dan pengembangan software jika ditemukan kesalahan atau perlu penambahan data baru.

\section{- Teknik Pengumpulan Data}

Sumber data berasal dari KUK dalam elemenelemen kompetensi (EK) pada tiap unit kompetensi (UK) sebagai penyusun model kompetensi (MK) Network Administrator. Pada tiap KUK dikategorikan berdasarkan spek-aspek kompetensi dengan indikator-indikator sebagai dimensinya. 
Indikator-indikator tersebut berupa taksonomi Bloom yang memiliki skor bertingkat.

Pada penelitian ini skor indikator ditetapkan pada dimensi $\mathrm{C}$ maka $\mathrm{C} 1$ skornya adalah 1 sampai C6 dengan skor 6. Pada dimensi sikap kerja, indikator A1 ditetapkan dengan skor 1 sampai dengan A5 diberi skor 5. Pada dimensi keterampilan, indikator P1 ditetapkan skor 1 sampai dengan indikator P5 yang diberi skor 5. Indikator-indikator itu diperoleh dari aktivitas kerja yang diterjemahkan melalui rumusan kata operasional, seperti dibuat, diidentifikasi, dimanipulasi, disesuaikan, yang kemudian oleh penulis diberi skor.

Instrumen pengumpulan data berupa Lembar Observasi yang berisi tentang petunjuk untuk mengidentifikasi data sesuai dengan definisi operasinal variabel penelitian.

\section{- Teknik Analisis Data}

Sesuai dengan tipe atau jenis penelitian ini maka teknik analisis data adalah deskriptif-evaluatif. Analisis data secara deskriptif ditujukan untuk memperoleh gambaran tentang pemetaan data-data multidimensi yang menyususn suatu model kompetensi. Analisis data secara evaluatif dimaksudkan untuk memperoleh komponenkomonen penyusun sistem OLAP yang kemudian dibandingkan dengan spesifikasi yang telah ditentukan.

\section{HASIL DAN PEMBAHASAN}

Sesuai prosedur penelitian, perencanaan sistem OLAP dimulai dari Requirement Step. Penulis menganalisis dan menentukan kebutuhan melalui analisis aspek-aspek kompetensi dalam suatu sistem OLAP yang sesuai untuk pemetaan model kompetensi. Model kompetensi yang menjadi objek penelitian adalah Network Administrator.

Pada OLAP dilakukan proses atau analisis data multidimensi, sehingga model kompetensi Network Administrator diurai menjadi aspek-aspek kompetensi penyusun model kompetensi tersebut sebagai data multidimensi.

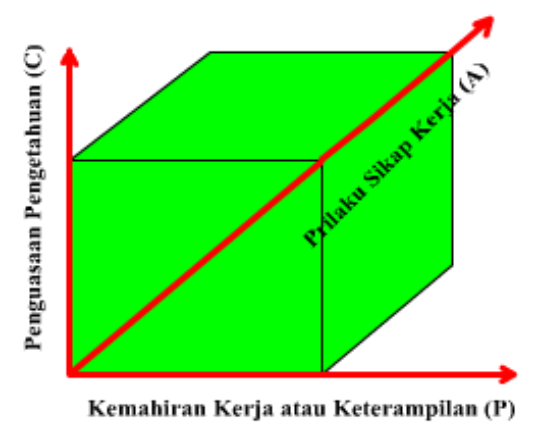

Gambar 2. Data Multidimensi KUK

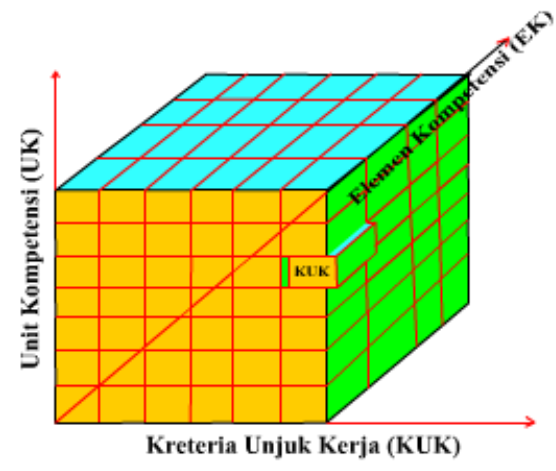

Gambar 3. Pemetaan data multidemensi suatu Unit Kompetensi

Model kompetensi Network Administrator ditemukan dimana satuan analisisnya adalah KUK. Dalam KUK dapat diurai menjadi data multidimensi, yang meliputi dimensi aspek penguasaan pengetahuan, dimensi aspek prilaku sikap kerja, dan dimensi aspek kemahiran kerja atau keterampilan, sebagaimana ditunjukkan pada gambar 2. Setiap dimensi memiliki indikator tingkatan atau taksonomi yang penulis lakukan analisis melalui referensi taksononomi Bloom. Berdasarkan taksonomi Bloom dapat diketahui indikator tingkatan penyususn kompetensi yang ditinjau dari dimensi aspek penguasaan pengetahuan, dimensi aspek prilaku sikap kerja, dan dimensi aspek kemahiran kerja atau keterampilan. Pada gambar 3 ditunjukkan data multidimensi beberapa KUK menyusun suatu Elemen Kompetensi (EK), dan beberapa EK membangun satu Unit Kompetensi (UK).

Pada pelaksanaan prosedur penelitian yang kedua penulis melakukan proses spesifikasi sistem OLAP yang menggunakan analisis kebutuhan sebagai acuannya. Model kompetensi (MK) terurai menjadi beberapa UK, dan setiap UK terurai menjadi beberapa EK, struktur dimensinya ditunjukkan melalui gambar 4 .

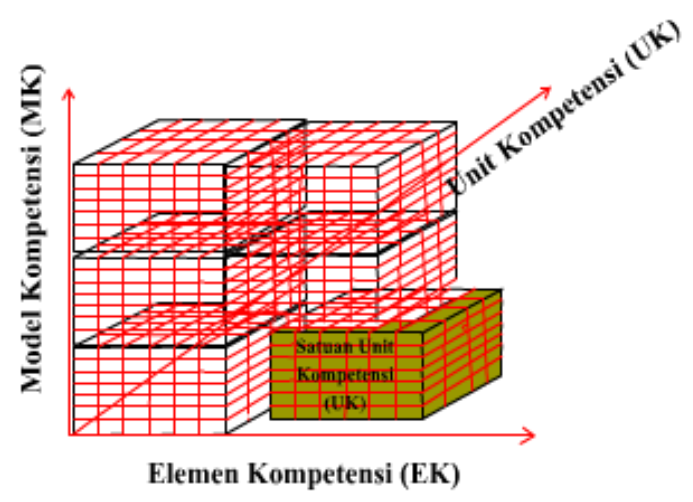

Gambar 4. Pemetaan data dimensional model kompetensi 
Secara conceptual modelling, data yang bersifat historical data dan multidimensional dari hasil analisis dalam suatu unit analisis secara dinamis disimpan ke dalam skema data multidimensi, kemudian divisualisasikan, baik dalam bentuk dashboard yang dilengkapi navigasi sebagai interface data ke pengguna awam agar query dilakukan secara interaktif maupun laporan untuk membantu para pembuat keputusan.

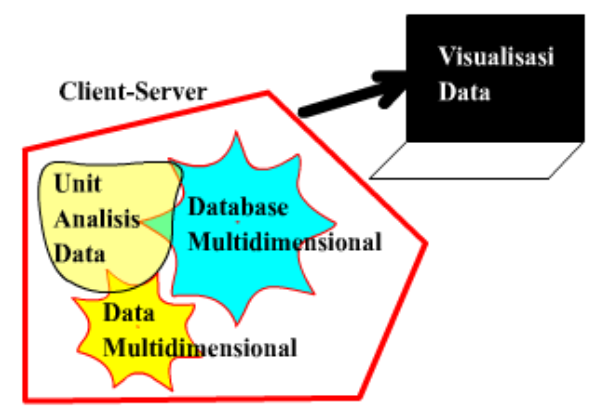

Gambar 5. Komponen-komponen penyusun sistem OLAP

Selain itu, sebagaimana ditunjukkan pada gambar 5 bahwa kompoen-komponen penyusun sistem OLAP dalam pemetaan model kompetensi dibutuhkan tersedianya dukungan arsitektur client-server untuk akses data yang cepat, kemampuan melakukan agregasi data.

Diperoleh temuan bahwa data KUK dapat diekstrak menjadi data multidimensi yang ditinjau dari dimensi aspek penguasaan pengetahuan, dimensi aspek prilaku sikap kerja, dan dimensi aspek keterampilan. Pada Tabel I menunjukan tentang rincian aspek kompetensi penyususun model kompetensi Network Administrator.

Tabel 1. Kalkulasi Jumlah Aspek-Aspek Kompetensi Penyusun Model Kompetensi Network Administrator

\begin{tabular}{|l|c|c|c|c|c|}
\hline $\begin{array}{c}\text { Unit } \\
\text { Kompetensi }\end{array}$ & $\begin{array}{c}\text { Elemen } \\
\text { Kompetensi }\end{array}$ & KUK & C & A & P \\
\hline Pertama & 2 & 9 & 9 & 9 & 9 \\
\hline Kedua & 3 & 6 & 6 & 6 & 6 \\
\hline Ketiga & 3 & 13 & 13 & 13 & 13 \\
\hline Keempat & 3 & 19 & 19 & 19 & 19 \\
\hline Kelima & 4 & 9 & 9 & 9 & 9 \\
\hline Keenam & 3 & 6 & 6 & 6 & 6 \\
\hline Ketujuh & 5 & 11 & 11 & 11 & 11 \\
\hline Kedelapan & 3 & 14 & 14 & 14 & 14 \\
\hline Kesembilan & 3 & 6 & 6 & 6 & 6 \\
\hline \multicolumn{1}{|c|}{ Jumlah } & 29 & 93 & 93 & 93 & 93 \\
\hline
\end{tabular}

\section{Keterangan:}

Pertama: Unit kompetensi tentang Merancang Topologi Jaringan; Kedua: Unit kompetensi tentang Merancang Keamanan Jaringan; Ketiga: Unit kompetensi tentang Mengkonfigurasi Routing pada Perangkat Jaringan antar Autonomous System;
Keempat: Unit Kompetensi tentang Memonitor Keamanan dan Pengaturan Akun Pengguna dalam Jaringan Komputer; Kelima: Unit Kompetensi tentang Mengatasi Serangan dalam Jaringan; Keenam: Unit Kompetensi tentang Mengidentifikasi Sumber Kerusakan; Ketujuh: Unit Kompetensi tentang Memperbaiki Kerusakan Konfigurasi Jaringan; Kedelapan: Unit Kompetensi tentang Mengoptimalkan Kinerja Sistem Jaringan; dan Kesembilan: Unit Kompetensi tentang Melakukan Backup dan Restore Konfigurasi Perangkat Jaringan.

Selanjutnya, pelaksanaan prosedur penelitian yang ketiga penulis melakukan perancangan software dengan menggunakan bahasa pemrograman Python dan package-package pendukung yang diperlukan, seperti Framework Django, Pandas, Numpy, Matplotlib, mplot3d, dan mpld3. Struktur database multidimensional yang penulis rancang sebagaimana ditunjukkan pada gambar 6 merupakan skema konsep (conceptual schema) yang perumusannya mengacu kepada hasil analisis penyusun KUK.

Selanjutnya dilakukan pengkodean, berupa rancangan konsep (conceptual konsep) secara logis, melalui penggunakan bahasa pemrograman Python yang didukung oleh package-package yang penulis tetapkan, seperti: Framework Django untuk mendukung fungsi Server dan rancangan database multidimensional, Numpy dan Pandas berfungsi untuk mendukung Unit Analisis Data, serta Matplotlib, mpl_toolkits, dan mpdl3 berfungsi untuk visualisasi data yang dipermudah dengan Bootstrap untuk dapat ditampilkan secara on line dan navigasi yang interaktif.

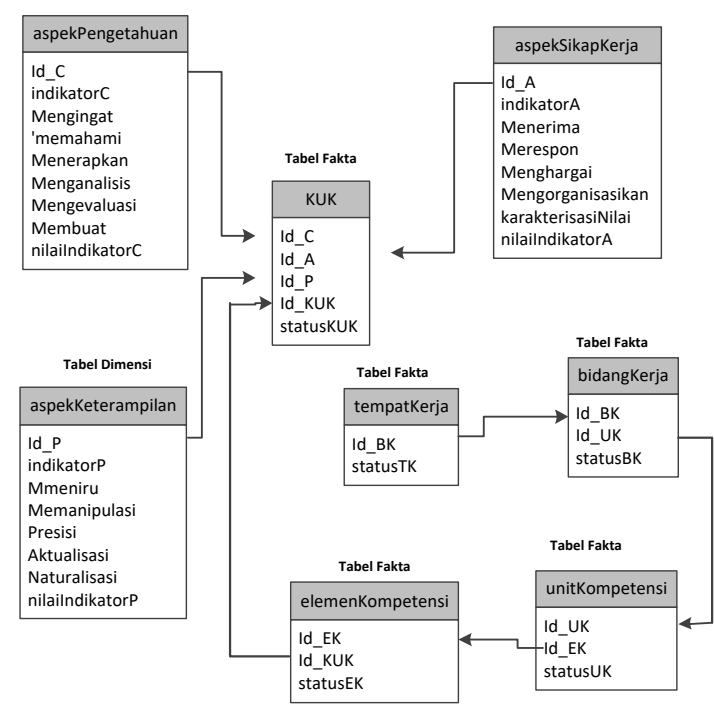

Gambar 6. Konsep Skema Database Multidimensional 
Pemanfaatan Django untuk membangun sistem OLAP ini dimulai dengan mendeskripsikan objek class models pada app sebagai database models. Tanpa menampilkan method kode models ditunjukkan sebagai berikut:

from django.db import models

class KUK(models.Model):

id_C=models.CharField(max_length $=5)$

id_A $=$ models.CharField(max_length $=5$ )

id_P=models.CharField(max_length=5)

id_KUK=models.CharField(max_length $=5$ )

statusKUK=models.CharField(max_length=50)

def__str_(self): return "\{\}.\{\}".format(self.id, self.statusKUK)

class aspekPengetahuan(models.Model):

id_C $=$ models.CharField(max_length $=5$ )

indikator $\mathrm{C}=$ models. CharField(max_length $=50$ )

mengingat $=$ models. CharField $($ max_length $=50$ )

memahami $=$ models.CharField(max_length $=50$ )

menerapkan=models.CharField $($ max_length $=50)$

menganalisis $=$ models.CharField $($ max_length $=50)$

mengevaluasi $=$ models.CharField(max_length $=50)$

membuat $=$ models.CharField $\left(\max \_\right.$length $\left.=50\right)$

nilaiIndikatorC $=$ models.IntegerField()

def__str_(self):

return " \{\}$.\{\}$ ".format(self.id, self.indikatorC)

class aspekSikapKerja(models.Model):

id_A=models.ChardField(max_length=5)

indikatorA=models.CharField(max_length=50)

kukNumber=models.IntegerField()

elemenKom=models.CharField(max_length $=50)$

unitKom=models.CharField(max_length $=50$ )

menerima $=$ models.CharField(max_length $=50$ )

merespon $=$ models. CharField $($ max_length $=50)$

menghargai=models.CharField(max_length=50)

mengorganisasikan=models.CharField $($ max_length $=50)$

karakterisasiNilai=models.CharField(max_length $=50$ )

nilaiIndikator $\mathrm{A}=$ models.IntegerField ()

def__str_(self): return " \{\}$.\{\} "$. format(self.id, self.indikatorA)

class aspekKeterampilan(models.Model):

id_P=models.ChardField(max_length=5)

indikatorP=models.CharField(max_length=50)

meniru=models.CharField(max_length $=50)$

memanipulasi=models.CharField(max_length $=50)$

presisi=models.CharField(max_length=50)

aktualisasi=models.CharField (max_length $=50)$

naturalisasi=models.CharField(max_length $=50$ )

nilaiIndikator $\mathrm{P}=$ models.IntegerField ()

def__str_(self): return " \{\}$.\{\}$ ".format(self.id, self.indikatorP)

class tempatKerja(models.Model):

id_BK=models.CharField(max_length=5)

statusTK=models.CharField(max_length=50)

def__str_(self): return " \{\}$.\{\}$ ".format(self.id, self.statusTK)

class bidangKerja(models.Model):

id_BK=models.CharField(max_length=5)

id_UK=models.CharField(max_length=5)

statusBK=models.CharField(max_length $=50$ )

def__str_(self): return " \{\}$.\{\}$ ".format(self.id, self.statusUK)

class unitKompetensi(models.Model):

id_UK=models.CharField(max_length=5)

id_EK=models.CharField(max_length=5)
statusUK=models.CharField(max_length=50)

def__str_(self): return " \{\}$.\{\}$ ".format(self.id, self.statusEK)

class elemenKompetensi(models.Model):

id_EK=models.CharField(max_length $=5$ )

id_KUK=models.CharField(max_length=5)

statusUK=models.CharField(max_length=50)

def__str_(self): return " \{\}$.\{\}$ ".format(self.id, self.statusEK)

Kemudian dilakukan mikemigration dan migrate. Pada app juga dilakukan pengkodean untuk class object forms, ditunjukkan sebagai berikut:

from django import forms

from .models import KUK, aspekPengetahuan, aspekSikapKerja, aspekKeterampilan, tempatKerja, bidangKerja, unitKompetensi, elemenKompetensi

class formKUK(forms.ModelForm):

class meta:

model=KUK

fields=['id_C','id_A','id_P', 'id_KUK']

class formKukC(forms.ModelForm):

class meta:

model=aspekPengetahuan

fields=['id_C','indikatorC','mengingat', 'memahami', 'menerapkan', 'menganalisis', 'mengevaluasi'

class formKukA(forms.ModelForm): 'membuat', 'nilailndikatorC']

class meta:

model=aspekSikapKerja

fields=['id_A','indikatorA','menerima', 'merespon','menghargai', 'mengorganisasikan', 'karakterisasiNilai', 'nilailndikatorA']

class formKukP(forms.ModelForm):

class meta:

model=aspekKeterampilan

fields=['id_P','indikatorP','mmeniru', 'memanipulasi','presisi', 'aktualisasi','naturalisasi' 'nilaiIndikatorP'] ]

class formTK(forms.ModelForm):

class meta:

model=tempatKerja

fields $=[$

'id_TK','id_BK','statusTK']

class formBK(forms.ModelForm):

class meta:

model=bidangKerja

fields=[ 'id_BK','id_UK','statusBK']

class formUK(forms.ModelForm):

class meta:

model=unitKompetensi

fields=['id_UK', 'id_EK', 'statusUK' ]

class formEK(forms.ModelForm):

class meta:

model=elemenKompetensi

fields=['id_EK','id_KUK', 'statusEK' ]

Pada setting database digunakan sqlite3, yang dikodekan sebagai berikut:

DATABASES $=\{$ 


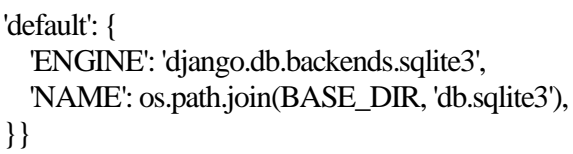

Analisis data yang berasal dari database dilakukan menggunakan bahasa Python dengan pakage Numpy dan Pandas. Visualisasi data digunakan pakage python yaitu matplotlib, mpl_toolkits.mplot3d, dan mpld3. Data penelitian diperoleh dari analisis KUK yang dievaluasi dengan menggunakan indikator taksonomi Bloom. Berdasarkan indikator taksonomi, yang terendah diberi nilai 1 dan tertinggi diberi nilai 6 untuk aspek pengetahuan, nilai 5 untuk aspek sikap kerja, nilai 5 untuk aspek keterampilan.
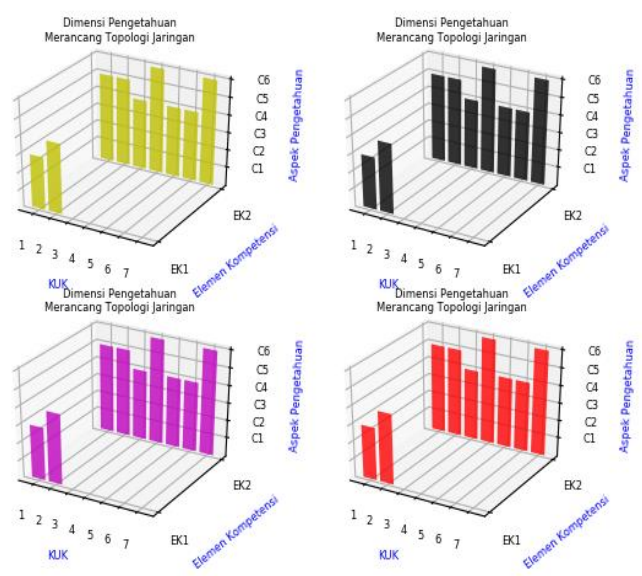

Gambar 7. Visualisasi dashboard OLAP dimensi aspekaspek kompetensi dari suatu unit kompetensi

Selanjutnya sesuai dengan prosedur penelitian, dilakukan kuasi-eksperimen terhadap sistem OLAP yang dibangun dalam rangka pengujian dari rancangan software OLAP yang telah dibuat. Berdasarkan pelaksanaan pengujian dapat ditampilkan visualisasi datanya. Pada gambar 7 ditunjukan visualisasi data KUK ditinjau dari dimensi penyebaran indikator taksonomi pengetahuan, dimensi sikap kerja, dan dimensi keterampilan pada tiap EK dalam UK Merancang Topologi Jaringan.

Melalui prosedur pengujian yang sama juga dapat divisualisasikan tentang penyebaran indikator-indikator dimensi aspek-aspek kompetensi pada 8 UK yang lainnya, diantaranya: Merancang Keamanan Jaringan, Mengkonfigurasi Routing pada Perangkat Jaringan antar Autonomous System, Memonitor Keamanan dan Pengaturan Akun Pengguna dalam Jaringan Komputer, Mengatasi Serangan pada Jaringan, Mengidentifikasi Sumber Kerusakan, Memperbaiki Kerusakan Konfigurasi Jaringan, Mengoptimalkan
Kinerja Sistem Jaringan, dan Melakukan Backup dan Restore Konfigurasi Perangkat Jaringan.

Pada gambar 8 menunjukkan hasil pengujian sistem OLAP yang mendeskripsikan tentang Proporsi antara indikator taksonomi pengetahuan, sikap kerja, dan keterampilan tiap KUK setiap EK terhadap dimensi UK pada suatu MK Network Administrator diperoleh aspek-aspek kritis kompetensi yang menandakan indicator penentu seseorang kompeten melakukan aktivitas kerja tersebut. Penyebaran aspek-aspek kritis kompetensi pada setiap UK dalam MK.

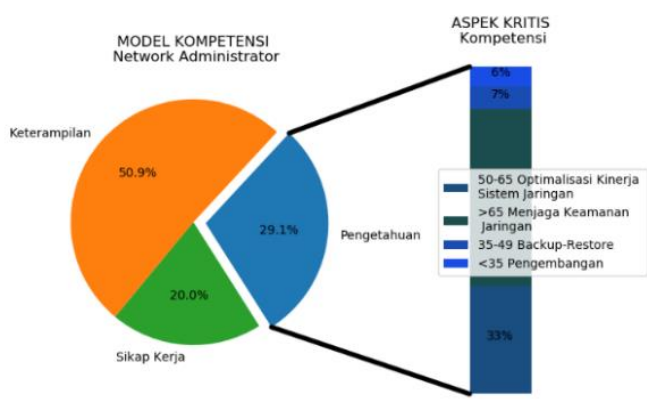

Gambar 8. Proporsi Aspek Kritis Kompetensi MK Netrwork Administrator

Pada gambar 9 ditunjukkan tentang dashboard sistem OLAP untuk pemetaan model kompetensi. Dari dashboard tersebut ditampilkan prosentase aspek penyusun KUK dan level interval KUK dalam mengembangkan profesi seseorang menjadi Administrator Jaringan. Keberhasilan seseorang sebagai Network Administrator sangat bergantung utamanya pada penguasaan tentang menjaga keamanan jaringan dari berbagai serangan dan ancaman, selanjutnya secara urut ke bawah tingkat aspek kritis kompetensinya yaitu optimalisasi kinerja sistem jaringan, backup dan restore konfigurasi sistem, dan pengembangan jaringan.

Kegiatan penelitian yang terakhir penulis melakukan analisis dan evaluasi dari kemungkinan software sistem OLAP ditemukan kesalahaan atau perlu ada penambahan data baru. Hal tersebut terkait dengan persyaratan untuk penyediaan navigasi sebagai interface data ke pengguna awam agar query dilakukan secara interaktif ditampilkan melalui Dashbord Web. Penyediaan dukungan arsitektur client-server sehingga berfungsi sebagai server informasi dengan akses data yang cepat telah dikembangkan melalui implementasi framework Django dan Bootstrap.

Analisis data secara dinamis melalui pemanfaatan teknik analisis data multidimensi telah dirumuskan dalam analisis KUK dalam EK setiap UK pada MK Network Administrator. Penyimpanan 
data ke dalam skema data multidimensi telah dirumuskan dalam skema database multidimensional Sqlite3. Kemampuan melakukan agregasi data telah digunakan dengan diperolehnya aspek-aspek kritis kompetensi. Data bersifat historis (historical data) masih ditunjukan pada waktu kebutuhan kompetensi yang sama. Penampilan dan formulasi model analisis data multidimensi untuk membantu para pembuat keputusan yang ditunjukan dengan ditampilkannya proporsi aspek-aspek kompetensi dalam KUK dan aspek kritis kompetensi dalam MK Network Administrator.

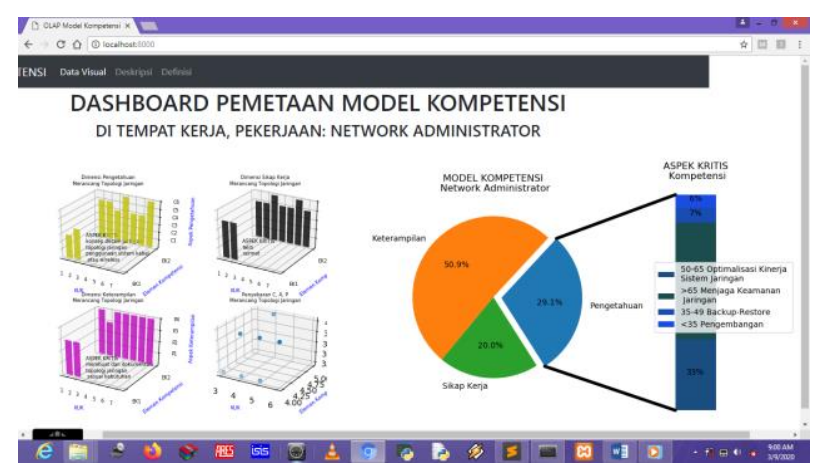

Gambar 9. Dashboard sistem OLAP untuk pemetaan model kompetensi

Pemetaan model kompetensi bidang kerja Administrasi Jaringan dari Dashboard sistem OLAP pada gambar 8 dan gambar 9 ditunjukan bahwa proporsi aspek kritis pembentuk profesi seseorang sebagai Administrator Jaringan di tempat kerja adalah 50,9\% aspek keterampilan, 29,1\% aspek pengetahuan, dan $20 \%$ aspek sikap kerja, dengan level unjuk kerja dalam unit kompetensi yang diperlukan pada interval di atas 65 sampai dengan100 adalah menjaga keamanan jaringan, interval 50 sampai dengan 65 adalah optimalisasi kinerja sistem jaringan, interval 35 sampai dengan 49 adalah backup-restore, dan interval di bawah 35 adalah kompetensi pengembangan. Level unjuk kerja dengan interval angka makin tinggi maka unit kompetensi tersebut makin diperlukan.

\section{PENUTUP}

\section{Kesimpulan}

Bertitik tolak dari tujuan penelitian dan pembahasan temuan hasil penelitian, penulis memperoleh simpulan sebagai berikut:

a. Rancangan sistem OLAP berbasis pemrograman python melalui pemetaan model kompetensi dapat menunjukan aspek-aspek kritis kompetensi dalam suatu model kompetensi. Pemetaan model kompetensi bidang kerja Administrasi Jaringan dari Dashboard sistem OLAP ditunjukan bahwa proporsi aspek kritis pembentuk profesi seseorang sebagai Administrator Jaringan di tempat kerja adalah 50,9\% aspek keterampilan, 29,1\% aspek pengetahuan, dan $20 \%$ aspek sikap kerja, dengan level unjuk kerja dalam unit kompetensi yang diperlukan pada interval di atas 65 sampai dengan100 adalah menjaga keamanan jaringan, interval 50 sampai dengan 65 adalah optimalisasi kinerja sistem jaringan, interval 35 sampai dengan 49 adalah backup-restore, dan interval di bawah 35 adalah kompetensi pengembangan. Level unjuk kerja dengan interval angka makin tinggi maka unit kompetensi tersebut makin diperlukan.

b. Sistem OLAP dapat menjadi salah satu pilihan media konektivitas untuk menjembatani transformasi pengetahuan, baik teoritis maupun praktis. Model kompetensi di tempat kerja dapat diekstrak menjadi struktur database multidimensional, yang dianalisis dari dimensi pengetahuan, dimensi sikap kerja, dan dimensi keterampilan.

c. Komponen-komponen dalam sistem OLAP untuk pemetaan model kompetensi meliputi data multidimensi, database multidimensi, arsitektur client-server, query atau akses data, dan visualisasi data atau informasi dalam multidimensi, sehingga rancangan sistem OLAP diorientasikan untuk mendeskripsikan tentang indikator-indikator aspek kompetensi pada setiap kriteria unjuk kerja dalam elemen kompetensi pada unit kompetensi atau model kompetensi tersebut.

\section{Saran}

Berdasarkan simpulan yang diperoleh dan dalam upaya mengembangkan konektivitas dan transformasi pengetahuan dari tempat kerja ke lembaga pendidikan vokasi melalui OLAP maka disampaikan saran-saran sebagai berikut:

a. Secara praktis, bahwa sistem OLAP untuk pemetaan model kompetensi dapat menjadi salah satu alternatif sumber data untuk pengembangan kurikulum pendidikan vokasi dan perumusan profil lulusan dari pendidikan vokasi tersebut.

b. Pengembangan teori, dimana kompetensi vokasional terdiri dari pengetahuan yang tersembunyi dan pengetahuan yang tampak, penerapan sistem OLAP untuk pemetaan model kompetensi diorientasikan sebagaian besar untuk menyingkap pengetahuan-pengetahuan yang tersebunyi tersebut. Oleh karena itu, penulis menyarankan agar perlu dikembangkan konsep, dan teori tentang rancangan sistem OLAP yang lain, diantaranya memanfaatkan teknologi machine learning atau deep learning.

c. Penelitian lanjutan, dimana adanya beberapa keterbatasan dalam penelitian ini maka kepada peneliti lain yang mengadakan penelitian sejenis diharapkan sumber data diperoleh dari tempat kerja langsung dengan input data melalui 
teknologi Extract, Transformation, and Load (ELT) atau teknologi online lainnya.

\section{Ucapan Terima Kasih}

Penulis merasa bersyukur ke hadirat Allah Subhanahu Wa Ta'ala atas selesainya penelitian ini sehingga dapat menjadi sebuah artikel ilmiah. Ucapan terimakasih penulis sampaikan kepada:

a. Ketua program studi Teknik Informatika Politeknik Negeri Indramayu yang telah mengijinkan Research Center sebagai tempat penelitian ini.

b. Direktur Politeknik Negeri Indramayu yang telah memberikan legalitas terhadap kegiatan penelitian ini.

c. Semua pihak yang telah memberikan dukungan dan bantuan sehingga penelitian ini dapat terlaksana.

\section{DAFTAR PUSTAKA}

Anonim. 2018. Booklet Survei Angkatan Kerja Nasional Agustus 2018. BPS Republik Indonesia.

Ennis, M. R. 2008. "A Review of the Literature and The Role of the Employment and Training Administration (ETA)". Pilots and Demonstration Team Division of Research and Evaluation Office of Policy Development and Research Employment and Training Administration U. S. Department of Labor.

Finlay, I., Stuart N., dan Stephanie, Y. 2005. "Changing Vocational Education And Training: An international comparative perspective". London This: the Taylor \& Francis e-Library.

Fogg, C. D. 1999. "Implementing your strategic plan: How to turn intent into effective action for sustainable change". New York: American Management Association.

InWEnt.(Eds).2009. "Final Report International Conference: Reorienting TVET Policy Toward Education for Sustainable Development". Berlin: UNESCO-UNIVOC dan CPSC.

Klein, A.D. (Eds). 2007. "Computer Software Engineering Research". New York: Nova Science Publishers, Inc.

Pratama, I.P.A.E. 2018. Handbook Data Warehouse: Teori dan Praktek Berbasiskan Open Source. Bandung: Informatika Bandung.
Setiawan, SRD (Eds).2019. Menteri PPN/Kepala Badan Perencanaan Pembangunan Nasional: Kelemahan Pendidikan Vokasi di Indonesia. https://money.kompas.com/read/2019/06/14/ 123000226/menurut-bappenas-inikelemahan-pendidikan-vokasi-diindonesia? page $=$ all.

Stenstr"om, M. dan Tynj"al"a, P. (Eds). 2009. "Towards Integration of Work and Learning Strategies for Connectivity and Transformation". Finlandia: Springer Science+ Business Media.

Wang L., Jajodia,S., Wijesekera, D., 2007. "Preserving Privacy in On-Line Analytical Processing (OLAP)". New York: Spinger.

Wrembel, R., Concilia, C. 2007. "Data Warehouses and OLAP: Concepts, Architectures and Solutions". London: IRM Press.

Zuppo, C. 2012. "Competency Models-An Overview". USA: Society for Human Resource Management (SHRM). 